

\title{
A Social Learning Space Grid for MOOCs: Exploring a FutureLearn Case
}

\author{
Kalpani Manathunga ${ }^{1}$, Davinia Hernàndez-Leo ${ }^{1}$, Mike Sharples ${ }^{2}$ \\ ${ }^{1}$ ICT Department, Universitat Pompeu Fabra, Barcelona, Spain \\ \{kalpani.manathunga, davinia.hernandez-Leo\}@upf.edu \\ ${ }^{2}$ Institute of Educational Technology, The Open University, Milton Keynes, UK \\ mike.sharples@open.ac.uk
}

\begin{abstract}
Collaborative and social engagement promote active learning through knowledge intensive interactions. Massive Open Online Courses (MOOCs) are dynamic and diversified learning spaces with varying factors like flexible time frames, student count, demographics requiring higher engagement and motivation to continue learning and for designers to implement novel pedagogies including collaborative learning activities. This paper looks into available and potential collaborative and social learning spaces within MOOCs and proposes a social learning space grid that can aid MOOC designers to implement such spaces, considering the related requirements. Furthermore, it describes a MOOC case study incorporating three collaborative and social learning spaces and discusses challenges faced. Interesting lessons learned from the case give an insight on which spaces to be implemented and the scenarios and factors to be considered.
\end{abstract}

Keywords: Collaborative Learning, Social Learning, MOOC

\section{$1 \quad$ Introduction}

The fact of putting students into groups does not ensure fruitful learning; rather effective collaborative learning must involve structured activities [1,2]. Adapting from Social Learning theory, which states that continuous mutual interactions positively influence the way humans learn [3], many MOOC platforms are moving towards providing social learning opportunities [1]. Yet, forum discussions which are the most widely exercised collaborative or social learning approach in massive learning contexts [4], have not seen very effective due to the overwhelming amount of threaded discussions which are difficult to follow [5]. Researchers highlight the absence of enhanced collaboration opportunities for MOOC learners [6, 7]. In this paper, we look into different possibilities of implementing collaborative and social learning aspects in MOOCs along with an exploratory study using three such learning spaces with a MOOC launched on the FutureLearn platform.

Computer Supported Collaborative Learning (CSCL) is the process of knowledge creation by enabling fruitful interactions mediated by technology $[1,2]$. Over decades CSCL activities have been applied at small scale in classrooms, but not widely used 
with large learning contexts, maybe because the scalability factor has not been properly considered in their design $[4,8]$. Social Learning may bring a sense of community, avoiding isolation in online learning and providing possibilities to learn from others [3]. Studies highlight potential benefits of forming sub communities and learner networks with positive encouragement $[7,9]$ and understanding emergent social structures in MOOC sub communities [6]. Social learning elements, provoking conversational learning and CSCL enforcing rich interactions, are not so easily adaptable or applicable in MOOCs, as they have been in a traditional classroom.

MOOCs have shown the possibility of designing learning at scale and pedagogy that can be driven by discussion and social networking conceptions, where the more people joining, the richer the interactions [8]. Existing fruitful collaboration methods such as tutorial groups, project teams or action learning sets, that work well in small scale settings, are difficult to scale $[7,8]$. Difficulties are mainly related to diversity in learner's motivations, expectations and differences in cultural expectations (e.g., how individuals should behave in social spaces) and therefore their behaviors when taking the MOOC $[9,10]$. However, some initiatives offering collaborative and social learning opportunities are emerging within MOOCs other than discussion forums, given the concern of implementing novel pedagogies and learning theories $[8,11]$. 'Study groups' provided by FutureLearn are local, private spaces for around 80 MOOC participants to discuss and share knowledge, 'cohort-specific discussion' by edX allows private group discussions visible only for a specific cohort, 'meet ups at learning hubs' by Coursera enable learners from nearby local to get-together for further discussions or project based learning and 'workspaces' from NovoEd support learning groups and project teams. Additionally, social networking spaces too provide scalable opportunities by allowing strangers to meet up and enhance connections which can be exploited in the context of education where social elements are complimented with learning $[9,12]$. Learner-centered groups introduced within MOOCs harnessing the benefits of social media like Facebook, Twitter, Google+ or Hangout have been seen as fruitful while enhancing learner experience $[9,12,13]$. Meet-ups, proposed by Coursera, require physical spaces and high levels of facilitation. Cohorts from edX lack novel pedagogical approaches for further interactions. Social media groups such as Facebook Groups are easy to implement, yet very challenging to monitor since interactions are free to emerge and many such groups can exist. Educators require more effort and additional support to structure interactions in such online spaces. Hence, deeper understanding is needed regarding different social and collaborative learning possibilities, to explore challenges and consider options to design suitable learning scenarios. It is equally important to investigate, for massive learner communities, pedagogical methods that have been shown to work well in classrooms, by bridging existing technological challenges.

This paper presents a social learning space grid, organizing diverse social interaction possibilities with underlying rationale, to be used by the MOOC community. We explore the case of a MOOC on 3D Graphics for Web Developers offered on the FutureLearn platform by Pompeu Fabra University, Spain, in which three different collaboration spaces were presented to support collaborative and social learning. We describe these spaces situating them within a proposed framework, identify learning 
design associated and the motive behind the usage of each space, and discuss examples of use and perceived challenges. Section 2 of the paper describes social learning spaces and presents the social learning space grid followed by diverse particularizations found from literature. In section 3, the MOOC case study is explained along with an analysis of the three collaboration spaces (Study Groups, PyramidApp, Conversational flows) adopted in the MOOC. The final section includes an accumulated discussion of lessons learned and challenges faced followed by concluding remarks and interesting future research directions as contributions from this exploratory study.

\section{Social Learning Space Grid}

\subsection{Social Learning Space Grid: Categories and the Rationale}

In order to lay a foundation to address collaborative and social learning aspects with their implications, this study proposes a collaboration space grid (Table 1), a social interaction framework, categorizing existing and prospective scalable collaboration techniques that can be offered within massive online courses. Apart from commonly picked collaboration spaces such as forums with multiple topic threads, dedicated discussion activities or cohort specific discussions in massive learning contexts [4], there can be other possibilities of implementing fruitful social interactions. Hence, the social learning space grid (Table 1) will be useful to study the dimensions of possible interactions, respective elements and how these can be used in open online courses. One important dimension is to study how far collaborations can be structured, using which elements. Unconstrained, long-lasting collaborations exist throughout the course lifetime and beyond. Also there exist ephemeral collaborations, constrained to an allocated task or for a given time period. Another dimension of the grid is the size factor affecting interactions. In a MOOC, all the course participants can interact in a common space, or it can be drilled down to small group level collaborations where 15 to 30 participants are grouped into one collaboration space. Moreover, the group sizes can be incrementally growing over the constraints like time or task providing cumulative interactions enriching collaborations.

Table 1. Social Learning Space Grid

\begin{tabular}{|c|c|c|c|}
\hline & Small & Increasing size & Whole cohort \\
\hline $\begin{array}{l}\text { Time and } \\
\text { Task } \\
\text { Uncon- } \\
\text { strained }\end{array}$ & $\begin{array}{l}\text { Groups exist throughout } \\
\text { the course. Participants } \\
\text { are free to interact at any } \\
\text { given moment, for any } \\
\text { given task. }\end{array}$ & $\begin{array}{l}\text { Small groups can be joined } \\
\text { based on certain criteria or } \\
\text { behavior to interact at any } \\
\text { time, for any given task. }\end{array}$ & $\begin{array}{l}\text { An open space for all course } \\
\text { participants to interact regard- } \\
\text { ing any topic at any time }\end{array}$ \\
\hline $\begin{array}{l}\text { Task } \\
\text { con- } \\
\text { strained }\end{array}$ & $\begin{array}{l}\text { Small groups formed to } \\
\text { attend a given task }\end{array}$ & $\begin{array}{l}\text { Small groups are combined } \\
\text { based on task completion to } \\
\text { attend another given task }\end{array}$ & $\begin{array}{l}\text { All course participants attend } \\
\text { given task in a common } \\
\text { interaction space }\end{array}$ \\
\hline $\begin{array}{l}\text { Time } \\
\text { con- } \\
\text { strained }\end{array}$ & $\begin{array}{l}\text { Small groups formed to } \\
\text { work during a specific } \\
\text { time period }\end{array}$ & $\begin{array}{l}\text { Small groups are combined } \\
\text { based on time expiration to } \\
\text { work together for another } \\
\text { specific time period }\end{array}$ & $\begin{array}{l}\text { All course participants attend } \\
\text { in a common interaction space } \\
\text { during a specific time period }\end{array}$ \\
\hline
\end{tabular}




\subsection{Particularizations of the Social Learning Space Grid}

Table 2 illustrates several examples found in the literature and possible novel interaction mechanisms. Meet-ups at learning hubs by Coursera suggest local physical locations for learners to engage in collaborative learning activities or to clarify content related issues. Such meet-ups can be of varying size depending on the number of learners reaching the particular learning hub. Content-wide and course-wide cohorts on the edX platform, offer different types of interaction environments for MOOC participants where course designers can decide to allow unconstrained cohort experience by opening up cohort specific MOOCs or only certain content are made visible for specific cohorts. Most widely used general forums can attract all participants, leading to massive amounts of threaded discussions if forums are not constrained to tasks or time. In a massive community, small groups can be joined based on certain criteria (e.g., being active or time allocated or task allocated). Time-constrained weekly small groups or weekly forums accessible for all course participants are other possibilities of enabling interaction in MOOCs.

Table 2. Social Learning Space Grid with Examples

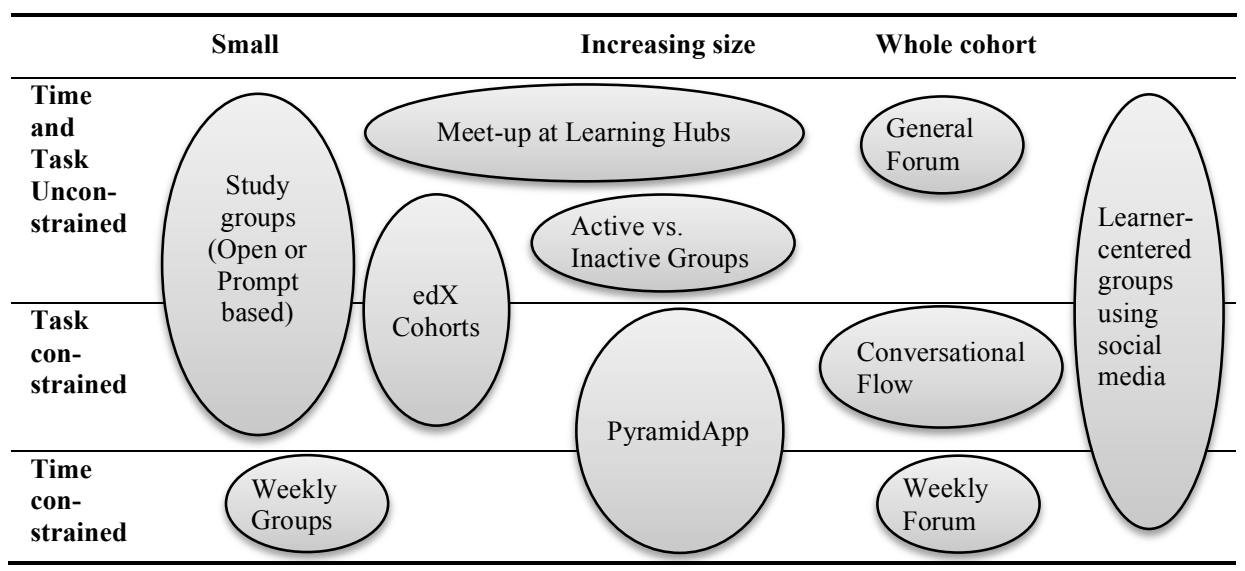

The FutureLearn MOOC platform has been developed on a social constructivist pedagogy that promotes effective learning through conversations [10]. FutureLearn MOOCs employ several levels of conversation flows including discussion steps for topic-related learner conversations, a space for comments and replies alongside every activity step for content clarifications and Study Groups to enable small group discussions or more focused group learning opportunities and such groups are consistent throughout the course. Participants are free to leave one group and join the next available, active group. Study groups can be implemented as either open group forums where up to a maximum of 80 MOOC learners are given the opportunity of sharing their learning experiences in a private local space, promoting free interactions that are not constrained by a particular topic, activity or time with no or very little intervention by the educator. Alternatively those can be educator instructions or prompts based, project-based or critique groups that differ from FutureLearn free-flowing discussion 
steps and focused discussions. FutureLearn's other conversation flows fall into the task-constrained forums category which provide a wider collaboration space for the whole cohort. Learners are able to comment on and reply to any activity step (task) since each step is associated with a conversation flow dedicated to it. Similarly, dedicated discussion steps available in the platform, are also in the same category since those are connected with tasks. PyramidApp [14] is another collaboration space instance that permits growing collaborations based on task and time constraints. PyramidApp is a scalable collaborative pedagogical method inspired by the Pyramid (aka Snowball) collaborative learning flow pattern [15] facilitating small group activity with cumulative collaborations. A Pyramid flow starts with individual proposals being discussed in small groups which are iteratively joined into larger-groups till a consensus is reached upon at the global level. Such scenarios foster individual participation and accountability (equal opportunity for all, yet with singular contributions) and balanced positive interactions (opinions of all members count). After situating diverse interaction options on the grid, we adopted Study groups, conversation flows and PyramidApp complementing the interaction spaces offered by FutureLearn in the following case study.

\section{MOOC Case Study}

\subsection{Description}

"3D Graphics for Web Developers" is a 5-week MOOC, especially for web developers to develop high quality interactive $3 \mathrm{D}$ applications to run natively on a browser. It completed two runs in 2016 (First run from February-March and the second run from July-August) on the FutureLearn platform. The MOOC is mainly aimed at web developers, who have existing knowledge of JavaScript, with the theoretical and practical knowledge to start programming 3D graphics applications to run natively in web browsers. There were around 6000 enrolments in the first run of the MOOC and around 4500 enrolments in the second. The MOOC had two lead educators and one mentor to mediate the course. In both runs, the course had more than $10 \%$ fully participating learners who had completed at least $50 \%$ of all course activity steps. As explained in the social learning space grid (Table 2), this exploratory study used three diverse collaboration spaces: task-constrained educator prompt based study groups (only in the second run of the MOOC); PyramidApp with both task and time constraints, promoting cumulative collaborations for small groups to study together and conversation flows linked to course step for the whole cohort.

As explained in the previous section, FutureLearn platform promotes learning through conversations where each video material or article is facilitated with a discussion thread alongside. Moreover, FutureLearn "Study Groups" were offered to interested learners that were added up to groups of 30 when they clicked on the study group tab available once they access the course content. In this specific course, taskconstrained educator prompt-based study groups were offered where learners were expected to become active within the group when the educator sends a prompt and act accordingly. The prompts used were either to discuss a concept or to share artefacts 
created by learners within groups. To enable cumulative interactions causing collaborative knowledge building [5], PyramidApp [14] provided structured collaborations in a way that individuals proposed options (which can be a question, explanation or a $3 \mathrm{D}$ artefact) for a given task. Then, they teamed up to compare and discuss their proposals and, finally, propose a new shared 3D artefact or agree upon most relevant options. New larger groups were grown by iteratively combining previous groups in order to generate new agreed options. Provision of rating and discussing in a levelled structure ensured gradual exposure in a collaborative environment. Educators addressed or commented on the most highly rated options and learners are expected to improve knowledge in the critiquing and negotiation process. As pyramids are time and task constrained, once a set of pyramids reach the global level, another set of pyramids are initiated allowing late joiners to participate in the activity and emails are sent notifying about pyramid progression. Educators can easily monitor the activity progression, level by level along with the rated options and discussions happening within groups.

Table 3 shows example learning design of these collaborative and social learning spaces, how those were integrated in the MOOC and the steps along with the step identification to recognize the respective week that a particular learning step was offered (e.g., 1.10 represents week 1, step 10). Initially, there were only task constrained conversational flows for the whole cohort and PyramidApp for small group interactions. With the second run of the MOOC, the study groups feature was available in the platform and ephemeral small group interactions were expected through educator prompt-based study groups since those were dedicated to share course outcomes and created artefacts. More open-ended activities were allocated for conversational flows whereas PyramidApp was assigned for technical aspects discourse, in order to reduce educator's workload by filtering out the most interesting queries to attend to, rather than going through lengthy threads with specific technical issues as the course unveils. Study groups and conversational flows are built-in features of the FutureLearn platform whereas PyramidApp is an external application introduced as an external link within course activity step.

Table 3. Step activity design of the $2^{\text {nd }}$ MOOC run, across three collaboration spaces

\begin{tabular}{|lll|}
\hline \multicolumn{1}{|c|}{ Discussion steps } & \multicolumn{1}{c|}{ Prompt based Study group } & \multicolumn{1}{c|}{ PyramidApp steps } \\
\hline 1.2 Tell us about yourself! & $\begin{array}{l}\text { 1.4 Let's share what we know } \\
\text { about 3D graphics creation }\end{array}$ & $\begin{array}{l}\text { 1.8 Pose questions about WebGLS- } \\
\text { tudio }\end{array}$ \\
\hline $\begin{array}{l}\text { 2.1 What makes a 3D scene } \\
\text { look realistic? }\end{array}$ & $\begin{array}{l}\text { 2.6 Share your experiments in } \\
\text { WebGLStudio }\end{array}$ & $\begin{array}{l}\text { 3.5 Pose questions about Three.js } \\
\text { API and related utilities }\end{array}$ \\
\hline $\begin{array}{l}\text { 4.7 Share your insights about } \\
\text { your realistic earth scene }\end{array}$ & 4.5 Share your final 3D earth scene & $\begin{array}{l}\text { 5.3 Do you have concerns or ques- } \\
\text { tions about advanced 3D concepts? }\end{array}$ \\
\hline $\begin{array}{l}\text { 5.7 Your next steps in 3D } \\
\text { graphics programming }\end{array}$ & $\begin{array}{l}\text { 5.6 Can you create it? (Share solar } \\
\text { system) }\end{array}$ & \\
\hline
\end{tabular}

\subsection{Results and Observations}

Conversation flows were abundantly used in both runs, since every learner is familiar with this due to its presence at every educational step in the platform. Yet discussion steps get flooded easily with hundreds of comments /answers and suggestions, so for 
an educator or another learner, it can be challenging and time consuming to follow lengthy threads or to filter out relevant comments making knowledge building possibilities limited [5]. But the platform provides social networking concepts such as likes, following as filtering mechanisms and it was visible that some learners were using such features in the conversation flows. As the course content was very practical and programming oriented, some learners got lost and frustrated and they were seeking help from peers. Experts were offering help to novices by sharing their suggestions/ideas and experiences to solve technical problems they faced. For example, when Grant posted a DOMException error, Ihor stated that it was a local server issue, Sheila suggested to include images and Fabien suggested to try with own webserver to avoid the exception. Also they shared knowledge through programming code samples (e.g., what went wrong when they were trying to integrate the additional library, "Three.js" or which exceptions should be considered when configuring the localhost server) in the discussion steps. For late joiners' queries and comments, there were fewer interactions or support, maybe because by the time they join most learners had finished the course and left.

In task-driven educator prompt-based study groups, learners posted created artefacts and some learners encouraged others by using social features (likes, comments), positive critiques and suggestions. Study groups are consistent throughout the course and were mostly active upon receiving the educator's prompts at the beginning of each week (Fig.1). From 16 groups formed, 12 groups had 30 members joined whereas another two had 29 and 4 respectively. Just as in the overall MOOC, a decreasing trend of study group engagement was observed over the course lifetime. Fig. 1 also illustrates the participation patterns in each group (shaded areas represent amount of activity) over the 5 weeks with respective group IDs issued by the platform. The lengths of the shaded boxes are proportionate to the number of days that group members were actively participating (sharing artefacts or commenting). Apart from the three groups that showed no activity in the Study group, other groups showed some interesting clusters of engagement patterns. Most common behaviour (5 out of 12 active groups) was to engage in activities for three weeks from the day the group was formulated.

Fig. 1. Educator prompts (left-side view) and Study groups behaviors (right-side view)

\begin{tabular}{|c|c|c|c|c|c|c|c|}
\hline \multirow{4}{*}{$\begin{array}{l}\text { Don't forget to share your 3D solar system within your study } \\
\text { groups. Feel free to share external links from your own } \\
\text { website or YouTube or Flickr. }\end{array}$} & \multirow{4}{*}{$\begin{array}{l}5.6 \text { Can you create } \\
\text { it? }\end{array}$} & Group ID & Week 1 & Week 2 & Week 3 & Week 4 & Week 5 \\
\hline & & $\begin{array}{l}753 \\
\end{array}$ & & & & & \\
\hline & & 784 & & & & & \\
\hline & & 793 & & & & & \\
\hline \multirow{5}{*}{$\begin{array}{l}\text { How is the activity going? Do you enjoy sharing and } \\
\text { discussing about your final earth scene within your study } \\
\text { groups? Some groups have a ready started sharing the } \\
\text { "Earth" scene, very interesting to see! }\end{array}$} & \multirow{5}{*}{$\begin{array}{l}4.5 \text { Share your fina } \\
3 \mathrm{D} \text { earth scene in } \\
\text { the study group }\end{array}$} & $\begin{array}{l}799 \\
802\end{array}$ & & & & & \\
\hline & & 810 & & & & & \\
\hline & & 818 & & & & & \\
\hline & & 826 & & & & & \\
\hline & & 834 & & & & & \\
\hline \multirow{3}{*}{$\begin{array}{l}\text { Still you are not late to share the creations! We saw some } \\
\text { very nice } 3 \mathrm{D} \text { creations in last week. Share your experiences } \\
\text { with your fellow learners. }\end{array}$} & \multirow{3}{*}{$\begin{array}{l}2.6 \text { Share your } \\
\text { experiments in } \\
\text { WebGL and }\end{array}$} & 840 & & & & . & \\
\hline & & 862 & & & & & \\
\hline & & 969 & & & & & \\
\hline & & 976 & & & & & \\
\hline & & 1030 & & & & & \\
\hline
\end{tabular}

PyramidApp was also presented as another social interaction space, via an external link embedded in three different 'Article' steps. It allowed learners to submit queries 
individually and then discuss and negotiate among themselves on more interesting queries for the attention of the educators, leaving behind the ones already addressed or solved at earlier stages or during the discussion process. Fig. 2 shows how learners were curious and rate the questions. Those two questions were selected from the previous level (level 2) and participants in this level (top left hand corner in the screen) can rate then. In the discussion board, some had tried to answer these questions whereas others used it to discuss queries and state their opinions. In this way, the activity can be focused, narrowed down only to specific aspects targeted at specific situations that learners may require additional guidance related to the topic. As a different PyramidApp activity, learner artefacts were shared in groups to rate and critique and it shows that participants appreciated these artefacts and provided suggestions for further improvements like suggesting different materials to be used. PyramidApp used an email notification system to notify learners when subsequent levels were ready, notifying them about the timer values of that level to keep them updated about the activity. Learners who submitted emails received timely notifications. One final notification was sent informing about the selected options and where the answers for winning popular were available at the end of each pyramid.

Fig. 2. Sample PyramidApp scenario with selected options and discussions occurred

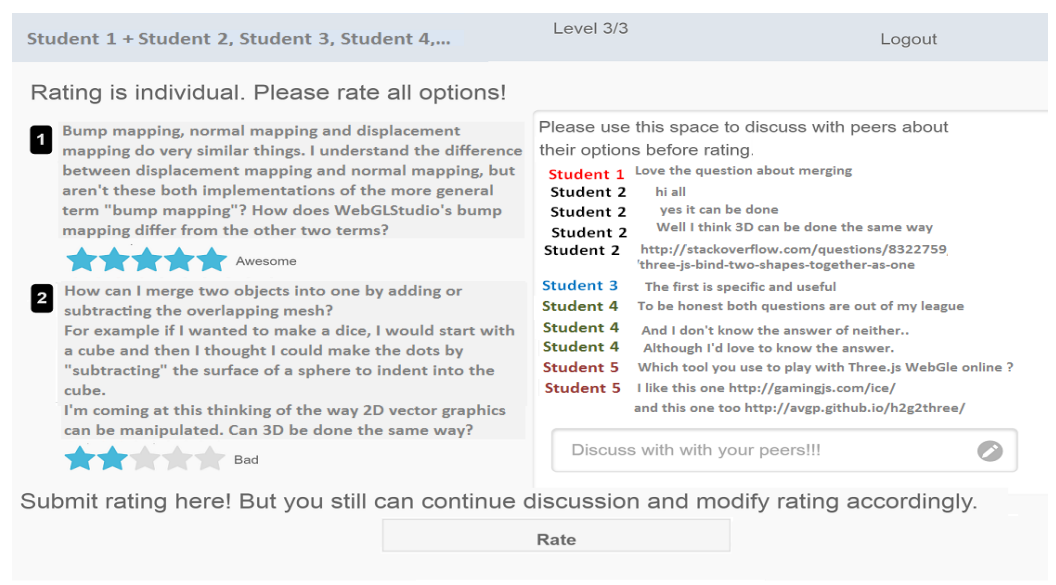

\section{Discussion on challenges faced}

It is an interesting viewpoint to understand design and implementation challenges related with three interaction spaces explored in the case study and other aforementioned collaboration spaces (Table 2). In the educator prompt-driven study groups, prompts are required to be carefully designed, more structured and precise. A specific prompt such as, "Does your first 3D scene look "realistic", "artistic" and "imaginative"? Share links to the work you created using WebGLStudio (or other similar tool), within your study group. Also appreciate others' creations by liking or commenting on the aspects that you like about those 3D scenes", would be more meaningful than just asking them to discuss. Course facilitators should constantly monitor groups and interfere if required by sending reminders as mid-week prompts. A better design of 
activities can be to allocate specific tasks to be done within the study groups and share the resulting conclusions in a related discussion step where the whole cohort can access. Synchronous interaction mechanisms in a MOOC can be futile because not many learners are present at the same time in a platform. Yet, with task and time constraining, to a certain extent, PyramidApp tries to achieve a level of synchronicity, facilitating learners at similar paces to continue their learning experience enriched by social interactions. Activity monitoring is feasible using the PyramidApp monitoring view along with groups and levels information. Existing approaches like meet ups incorporate challenges such as a requirement for physical locations to enact collaborative activities, lack of novel pedagogical approaches and activity structuring to provoke further interactions. Activity monitoring is also demanding in small open groups, since interactions are free to emerge and many such groups can exist, the educator needs more effort to monitor, and require additional support to structure interactions. Though techniques addressing the whole cohort such as forums, conversational flows or large social media groups are easily facilitated, it is difficult to monitor and challenging for knowledge building process [5] due to overwhelming amount of messages. On the contrary, weekly forums can be comparatively easier because of the weekly structure. Hence, a better strategy is to allow small groups to increasingly grow, joined based on certain criteria (e.g., being active or time allocated or task allocated) in a way that reduces the number of groups and with provision of technological facilitation for regrouping and activity monitoring to reduce educator's workload.

\section{Conclusion}

Implementing scalable pedagogies and novel learning opportunities promoting more learner collaborations in MOOCs is essential and necessary for those to become a disruptive innovation in education. Making MOOCs more social can lead to enjoyable learning experience and the proposed social learning space grid shows potential social interaction methods applicable with examples. The three interaction spaces (conversation flows, study groups and PyramidApp) tested in this case study reveal possible practical challenges such as enabling more structured activities, well-thought out course design and more engaging tasks. Frequently study groups deviated from intended tasks to become help-seeking groups or spaces to get to know each other. Even the conversational flows were not populated equally and late comers were not receiving responses and help as early joiners. Though many learners accessed PyramidApp some were not really engaging in rating and discussing but it was coping with latecomers successfully as new pyramids were created for the same task. Based on these lessons learnt, the activity design for the studied MOOC (e.g., prompts for study groups) has been revised for a third edition of the course. Moreover, future research directions include implementing (quasi-)experimental or experimental designs to study the impact (learning, behaviors, facilitation and monitoring requirements) of different spaces for potentially effective scalable pedagogy considering the social learning spaces and options and combinations of social learning spaces expressed in the grid. The Social Learning Space Grid dimensions provide useful tips for learning technologists to implement social interaction spaces in MOOCs. Based on course 
requirements suitable social learning spaces can be embedded providing richer interaction opportunities for MOOC learners.

Acknowledgements: This work has been partially funded by the Spanish Ministry of Economy and Competitiveness under RESET (TIN2014-53199-C3-3-R), the Maria de Maeztu Programme (MDM-20150502) and the RecerCaixa CoT project.

\section{References}

1. Dillenbourg, P.: Orchestration Graphs. EPFL Press, Switzerland (2015).

2. Hernández-Leo, D., Asensio- Pérez, J.I., Dimitriadis, Y., Villasclaras- Fernández, E.D.: Generating CSCL scripts. From a Conceptual Model of Pattern Languages to the Design of Real Scripts. In: Goodyear P.; Retalis, S. (Eds.). Technology-Enhanced Learning, Design patterns and pattern languages. Sense Publishers, Series Technology Enhanced Learning, 49-64 (2010).

3. Bandura, A.: Social learning theory. General Learning Press, USA (1971).

4. Manathunga, K., Hernández-leo, D.: Has research on collaborative learning technologies addressed massiveness? A literature review. Journal of Educational Technology \& Society. 18(4), 357-370 (2015).

5. Scardamalia, M., Bereiter, C.: Knowledge Building : Theory, Pedagogy, and Technology. Cambridge Handbook of the Learning Sciences. 97-118 (2006).

6. Rosé, C.P., Carlson, R., Yang, D., Wen, M., Resnick, L., Goldman, P., Sherer, J.: Social factors that contribute to attrition in MOOCs. First ACM Conference on Learning @ scale. 197-198 (2014).

7. Siemens, G., Gasevic, D., Dawson, S.: Preparing for the digital university: a review of the history and current state of distance, blended and online learning (2015).

8. Ferguson, R., Sharples, M.: Innovative pedagogy at massive scale: teaching and learning in MOOCs. In: Rensing, C., de Freitas, S., Ley, T., Muñoz-Merino, P.J. (Eds.) Open Learning and Teaching in Educational Communities, proceedings of $9^{\text {th }}$ European Conference on Technology Enhanced Learning, Graz, Austria. Heidelberg: Springer, 98-111(2014).

9. Alario-Hoyos, C., Perez-Sanagustin, M., Delgado-Kloos, C., Parada G., H., Munoz-Organero, M.: Delving into participants' profiles and use of social tools in MOOCs. IEEE Transactions in Learning Technologies. 7(3), 260-265 (2014).

10. Ferguson, R., Clow, D., Beale, R., Cooper, A.J., Morris, N., Bayne, S., Woodgate, A.: Moving through MOOCS: pedagogy, learning design and patterns of engagement. In: Klobucar, T., Conole, Grainne, C. (Eds.) Design for Teaching and Learning in a Networked World, proceedings of $10^{\text {th }}$ European Conference on Technology Enhanced Learning. Switzerland: Springer, 70-84 (2015).

11. Saadatdoost, R., Sim, A.T.H., Jafarkarimi, H., Mei Hee, J.: Exploring MOOC from education and Information Systems perspectives: a short literature review. Educational Review. 505-518 (2015).

12. Knox, J.: Digital culture clash: "massive" education in the E-learning and Digital Cultures MOOC. Distance Education. 35(2), 164-177 (2014).

13. Beaven, T., Hauck, M., Comas-Quinn, A., Lewis, T., Arcos, B.: MOOCs: Striking the Right Balance between Facilitation and Self-Determination. MERLOT Journal of Online Learning and Teaching. 10, 31-43 (2014).

14. Manathunga, K., Hernández-Leo, D.: PyramidApp: Scalable Method Enabling Collaboration in the Classroom. In: Verbert, K., Sharples, M., and Klobučar, T. (Eds.) Adaptive and adaptable learning, proceedings of $11^{\text {th }}$ European Conference on Technology Enhanced Learning, Lyon, France. Springer, 422-427 (2016).

15. Hernández-Leo, D., Villasclaras-Fernández, E.D., Asensio-Pérez, J.I., Dimitriadis, Y., Jorrín-Abellán, I.M., Ruiz-Requies, I., Rubia-Avi, B.: COLLAGE: A collaborative Learning Design editor based on patterns. Journal of Educational Technology \& Society. 9, 58-71 (2006). 